\title{
Sporopollenin in the Development of the Cellular Slime Moulds
}

\author{
By YASUO MAEDA \\ Biological Institute, Faculty of Science, Tohoku University, Aoba, Sendai 980, Japan
}

(Received 29 June 1984; revised 5 August 1984)

\begin{abstract}
The presence and location of an acetolysis-resistant polymer (sporopollenin) in various fruiting structures of the cellular slime moulds were demonstrated. Macrocysts (giant cells with thick cell walls) formed by a mutant (MF-1) of Dictyostelium mucoroides 7 contained large amounts of sporopollenin in their walls. In contrast, microcysts (round, walled resting cells) of Polysphondylium pallidum ws-320 lacked sporopollenin, at least in a tight networked form. This difference in sporopollenin distribution seems to be at least partly related to a difference in the germination efficiency of the two types of cells. In Acytostelium irregularosporum fruiting bodies, the acellular stalk was found to consist mainly of sporopollenin, but the spores lacked it in a tight networked form. Spores of Polysphondylium pallidum and $P$. violaceum contained sporopollenin in the wall region. All the above species belong to the class Dictyostelia. Fruiting bodies of Acrasis rosea, a member of the class Acrasea, lack a tight network of cellulose wall as well as sporopollenin. It is clear that slime mould sporopollenin shows unique distribution patterns depending upon cell type and species. The functional significance of sporopollenin is discussed, with special reference to the late developmental stages of slime mould cells.
\end{abstract}

\section{INTRODUCTION}

The presence of an acetolysis-resistant polymer (sporopollenin) has been widely reported in pollen exines of angiosperms and gymnosperms and also in spores of pteridophytes, fungi and algae (see Brooks et al., 1971). This polymer is undoubtedly responsible for the physicochemical strength of the cell walls. Sporopollenin is also present in the fruiting bodies of cellular slime moulds, assuming unique intra- and extra-cellular spatial pattenrs (Maeda, 1984). Sporopollenin in Dictyostelium discoideum, D. mucoroides and Polysphondylium violaceum fruiting bodies is localized in the stalk sheath as a bundle of fine fibrils ( $4-5 \mathrm{~nm}$ thick), while the distribution and fine structure in the spores vary from species to species (Maeda, 1984). The temporal and spatial patterns of sporopollenin synthesis are of particular importance for understanding the mechanism of sorocarp construction, because sporopollenin is usually formed at the tip region of a culminating cell mass, possibly prior to the cellulose wall of stalk cells. To further investigate the functions of sporopollenin in slime mould development, its distribution patterns in various kinds of slime mould cells were analysed by light and electron microscopy.

\section{METHODS}

Organisms and culture. Macrocysts were prepared from a mutant (MF-1) of Dictyostelium mucoroides 7 according to Amagai \& Filosa (1984). Microcysts were prepared by incubation of Polysphondylium pallidum ws-320 cells on an encystment medium as described by Toama \& Raper (1967). Spores of P. pallidum 1 and ws-320, and Acytostelium irregularosporum $\mathrm{C}-54$ were inoculated separately in association with Escherichia coli $\mathrm{B} / \mathrm{r}$ on LP-medium $\left(0.3 \%\right.$ lactose, $0.3 \%$ Bacto-peptone, $2 \%$ agar) and incubated for $6 \mathrm{~d}$ at $21-22{ }^{\circ} \mathrm{C}$ to obtain mature fruiting bodies. Acrasis rosea Ba78-1 cells were inoculated in association with Rhodotorula mucilaginosa on CDY-medium (1.9\% Difco corn meal agar, $0.1 \%$ yeast extract) and incubated for $8 \mathrm{~d}$ to obtain mature fruiting bodies, as described by Olive \& Stoianovitch (1960).

Acetolysis and electron microscopy. Samples on the agar plates were suspended in distilled deionized water (DDW) and collected by centrifugation $(3 \mathrm{~min}$ at $820 \mathrm{~g})$. The samples were treated with $10 \%(\mathrm{w} / \mathrm{v}) \mathrm{KOH}$ in a boiling water-bath for $45 \mathrm{~min}$, followed by two washings in DDW. Subsequently, the samples were acetolysed 


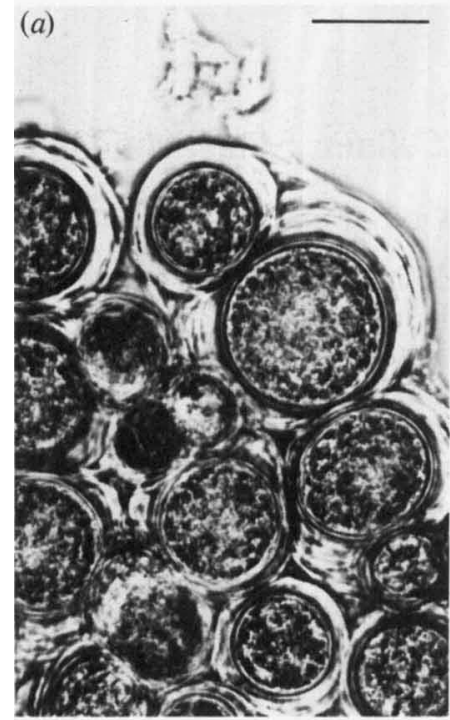

(c)

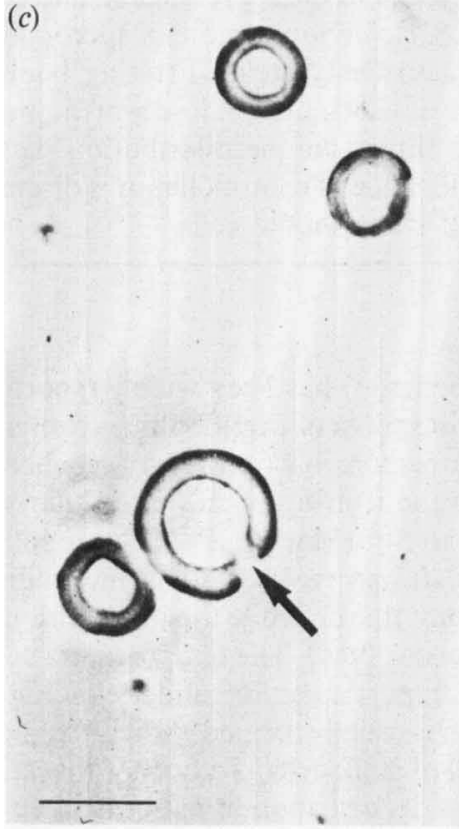

(b)

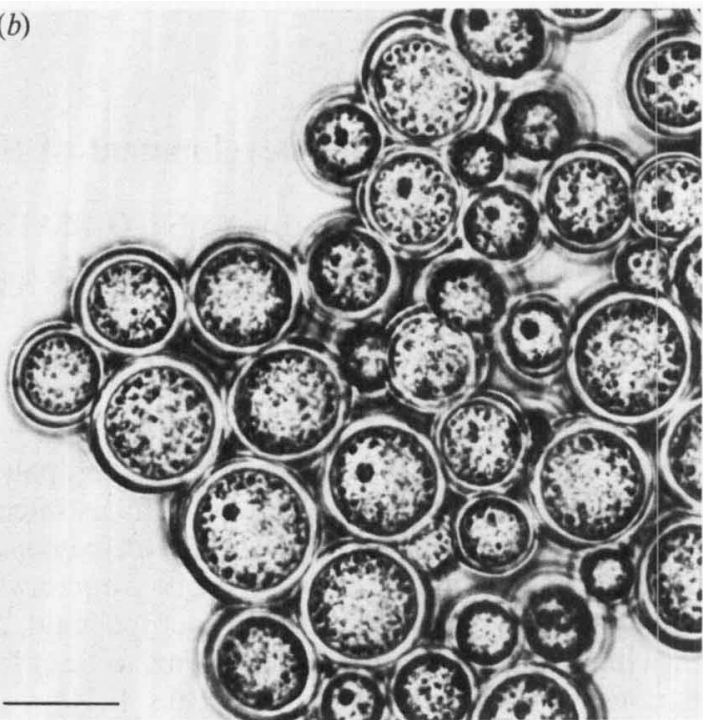

(d)

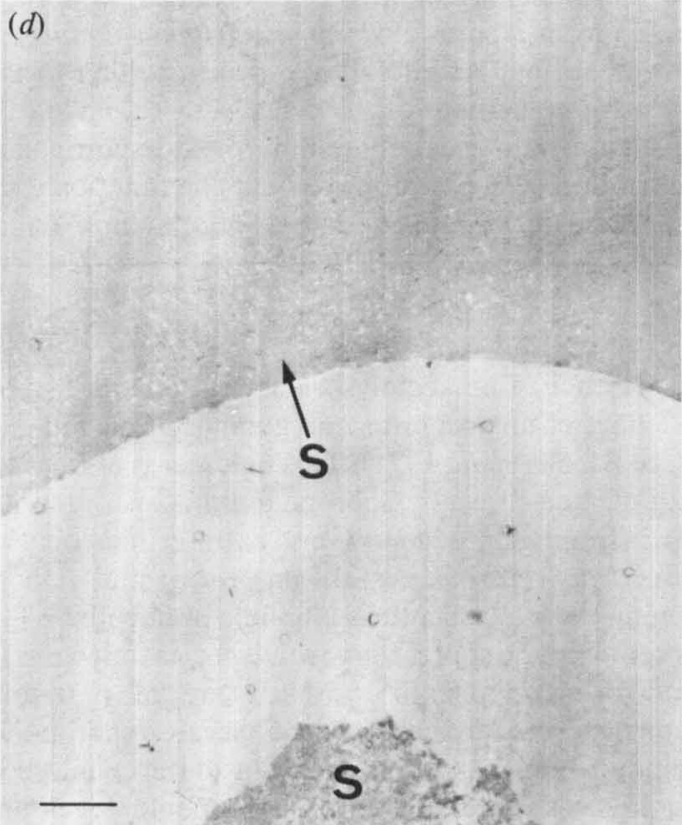

Fig. 1. Structural changes of macrocysts derived from a D. mucoroides 7 mutant during alkali- and acidtreatments. $(a, b, c)$ Phase-contrast micrographs. Bars, $20 \mu \mathrm{m}$. (a) Intact macrocysts with thick cell walls. (b) $\mathrm{KOH}$-treated macrocysts. The cytoplasm is less dense than that of the untreated macrocysts. (c) Acetolysed macrocysts. Only the wall materials remain, and sometimes a small portion of the wall is split (arrow), possibly by a mechanical shearing force. $(d)$ Electron micrograph of an acetolysed macrocyst. The sporopollenin (S) consists of moderately electron-opaque, amorphous structures. Bar, $1 \mu \mathrm{m}$.

using a slight modification of Erdtman's (1960) method, as reported previously (Maeda, 1984). After washing once in acetic acid, the samples were washed in DDW by centrifugation ( $5 \mathrm{~min}$ at $9000 \mathrm{~g}$ ).

The gross morphology of samples at each step was monitored by phase-contrast microscopy. For electron microscopy, the specimens were fixed in $2 \%(\mathrm{v} / \mathrm{v})$ glutaraldehyde, post-fixed in $1 \%(\mathrm{w} / \mathrm{v}) \mathrm{OsO}_{4}$, dehydrated in a graded series of ethanol solutions, and finally embedded in epoxy resin, as described previously (Maeda, 1984). Ultrathin sections (60-80 nm thick) were stained with lead citrate according to Reynolds (1963) and were observed with a Hitachi H-500 transmission electron microscope. 

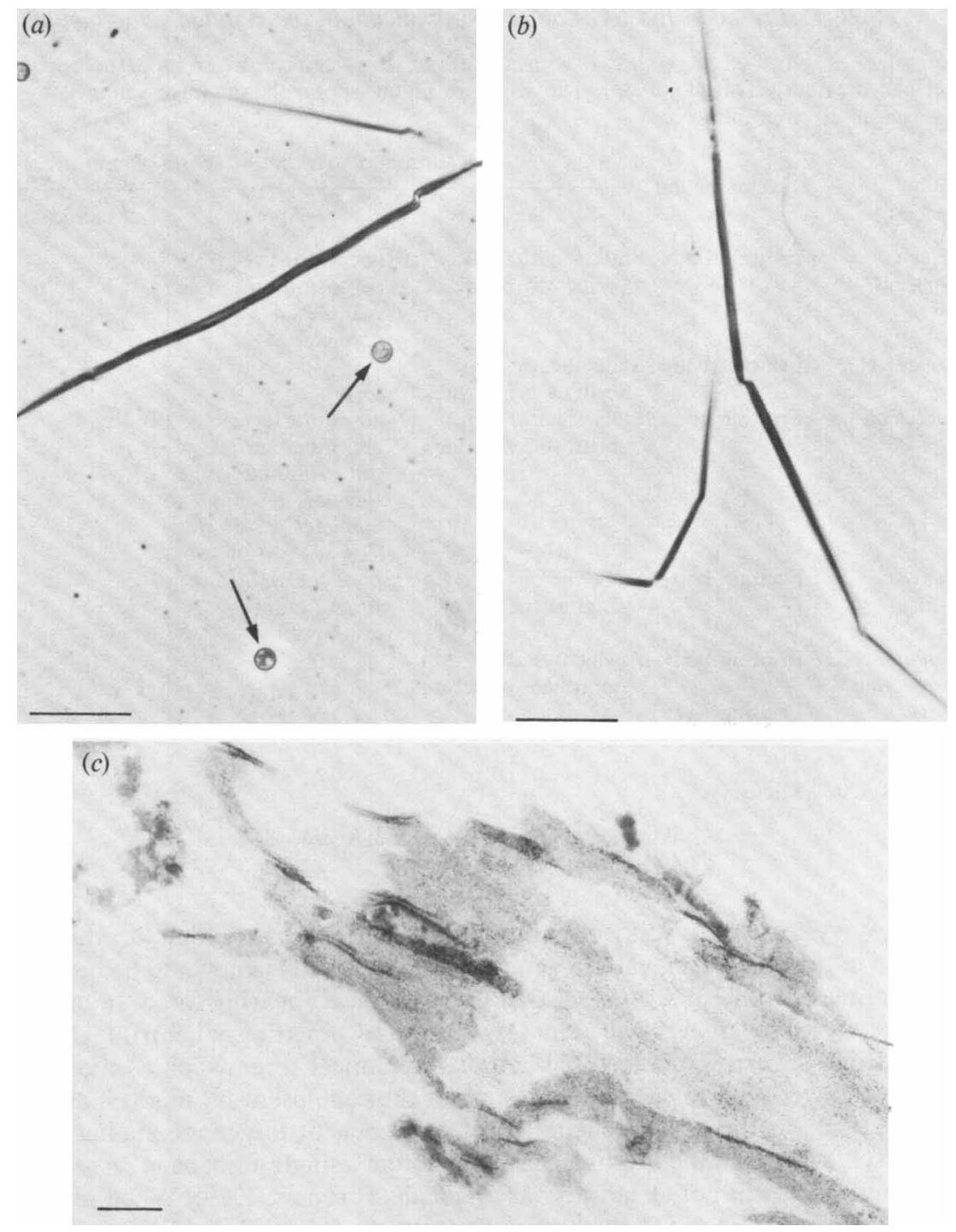

Fig. 2. $(a, b)$ Phase contrast micrographs of Acytostelium irregularosportum fruiting bodies. Bars, $20 \mu \mathrm{m}$ (a) Thin acellular stalk and round spores (arrows). (b) Acetolysed sample. Only the acellular stalk remains, all the spores being completely lysed. (c) Electron micrograph of an acetolysed stalk, which consists of amorphous structures with moderate electron density. Bar, $0.25 \mu \mathrm{m}$.

\section{RESULTS AND DISCUSSION}

Macrocysts of the cellular slime moulds are supposed to be true sexual systems with zygote formation and transient diploidy (MacInnes \& Francis, 1974). When mature macrocysts of $D$. mucoroides were treated with $\mathrm{KOH}$, their overall structure showed no appreciable change, while the cytoplasm seemed to become less dense as compared with untreated macrocysts (Fig. $1 a, b$ ). During subsequent acetolysis, the protoplasm was completely lost and only thick wall materials remained (Fig. 1 c), indicating the presence of a large quantity of sporopollenin in the macrocyst wall. Observation in the electron microscope revealed the acetolysed wall to be composed of moderately electron-opaque amorphous structures (Fig. 1d). Up to now it has been extremely difficult to make macrocysts germinate, and therefore there has been little genetic analysis using 
Table 1. Presence and location of sporopollenin in the cellular slime moulds

The structures indicated were treated with alkali and then acetolysed to obtain sporopollenin, as described previously (Maeda, 1984). The structure of the sporopollenin was examined by phasecontrast and electron microscopy.

\begin{tabular}{|c|c|c|c|c|}
\hline \multirow[b]{2}{*}{ Species } & \multirow{2}{*}{$\begin{array}{l}\text { Developmental } \\
\text { form }\end{array}$} & \multicolumn{3}{|c|}{ Location and structure of sporopollenin in: } \\
\hline & & Stalk & Spore & Macrocyst/microcyst \\
\hline $\begin{array}{l}\text { Dictyostelium } \\
\text { discoideum } \mathrm{NC}-4^{*}\end{array}$ & Fruiting body & $\begin{array}{l}\text { Stalk sheath: fine } \\
\text { fibrils, } 4-5 \mathrm{~nm} \text { thick }\end{array}$ & $\begin{array}{l}\text { Inner surface of } \\
\text { cell membrane: fine } \\
\text { granules, } 4-5 \mathrm{~nm} \\
\text { diameter }\end{array}$ & \\
\hline D. mucoroides $11^{*}$ & Fruiting body & $\begin{array}{l}\text { Stalk sheath: fine, } \\
\text { fibrils, } 4-5 \mathrm{~nm} \text { thick }\end{array}$ & - & \\
\hline $\begin{array}{l}\text { Polysphondylium } \\
\text { violaceum P6* }\end{array}$ & Fruiting body & $\begin{array}{l}\text { Stalk sheath: fine } \\
\text { fibrils, } 4-5 \mathrm{~nm} \text { thick }\end{array}$ & $\begin{array}{l}\text { Outermost layer of wall } \\
\text { and inner surface of } \\
\text { cell membrane: fine } \\
\text { spicules, } 4-5 \mathrm{~nm} \\
\text { diameter, } 25-50 \mathrm{~nm} \\
\text { long }\end{array}$ & \\
\hline $\begin{array}{l}P . \text { pallidum } 1 \\
\text { and ws- } 320\end{array}$ & Fruiting body & $\begin{array}{l}\text { Stalk sheath } \\
\text { (fragmented) }\end{array}$ & $\begin{array}{l}\text { Spore cell wall (fine } \\
\text { structure not } \\
\text { examined) }\end{array}$ & \\
\hline $\begin{array}{l}\text { Acytostelium } \\
\text { irregularosporum }\end{array}$ & Fruiting body & $\begin{array}{l}\text { Acellular stalk: } \\
\text { amorphous structure }\end{array}$ & - & \\
\hline Acrasis rosea & Fruiting body & - & - & \\
\hline $\begin{array}{l}\text { D. mucoroides } 7 \\
\text { mutant (MF-1) }\end{array}$ & Macrocyst & & & $\begin{array}{l}\text { Cell wall: amorphous } \\
\text { structure }\end{array}$ \\
\hline P. pallidum ws -320 & Microcyst & & & - \\
\hline
\end{tabular}

the macrocyst system. This difficulty might be at least partly due to the presence of sporopollenin in the macrocyst wall. In general, sporopollenin is known to be quite resistant to chemical treatments, while it is less resistant to mechanical shearing force. In fact, sometimes part of the acetolysed macrocyst wall seemed to be split by pipetting or centrifugation during the preparation (Fig. $1 c$, arrow). It is possible that mechanical forces such as those imposed by osmotic shock, in addition to enzymic digestion of the cellulose wall, might induce macrocyst germination. If this is the case, it should be of great benefit in genetic studies.

A microcyst is a round, walled resting cell formed from a single amoeba in response to osmotic or other stimuli in most if not all strains of $P$. pallidum (Francis, 1979). When microcysts of $P$. pallidum ws-320 were subjected to acetolysis, they were completely lysed, indicating the absence of a tight network of sporopollenin. This might be related to the fact that microcysts can germinate without the need for a period of dormancy or heat activation (O'Day, 1974).

During culmination of Acytostelium, all the cells secrete an acellular stalk and then turn into spores (Raper \& Quinlan, 1958). When fruiting bodies of Acytostelium irregularosporum were acetolysed, the spores were completely lysed and only tubular stalks, with a reddish pink colour, remained (Fig. 2). It is noteworthy that the acellular stalk is essential for the culmination process of Acytostelium and is composed mainly of sporopollenin.

As predicted in our previous work (Maeda, 1984), the spore cell wall of $P$. pallidum 1 and ws320 was found to contain sporopollenin. However, acetolysis of the stalk sheath caused marked fragmentation. It is phylogenetically somewhat strange that the stalk sheath has less tightly networked sporopollenin, because a related species, $P$. violaceum, has a tight network of sporopollenin covering a wide area of the stalk sheath.

All the species described so far are included in the class Dictyostelia (Olive, 1975). In contrast to Dictyostelia, members of the class Acrasea, which includes Acrasis rosea, exhibit different morphogenetic movement without discrete differentiation between spore and stalk cells (Olive $\&$ Stoianovitch, 1960). When Acrasis rosea fruiting bodies, consisting of round cells, were treated 
with $\mathrm{KOH}$, no structures remained. This suggests that Acrosis rosea cells lack a tight network of cellulose wall as well as sporopollenin.

Our results confirm that sporopollenin is widely distributed and uniquely localized in the cellular slime moulds, as summarized in Table 1, though the phylogenetic significance of this is still obscure. Little attention has been paid to the functional significance of sporopollenin synthesis in dynamic biological processes like morphogenetic movement and differentiation. The spatial pattern of sporopollenin, particularly in stalk-forming slime moulds, suggests that the biosynthesis and deposition of sporopollenin might be involved in developmental events like sorocarp formation as well as in the establishment of cell shape and rigidity. While the chemical nature of sporopollenin is still not fully characterized, the work of Shaw (1971) indicates that it is composed of oxidative polymers of carotenoid and/or carotenoid esters. Chemical analysis of slime mould sporopollenin will be facilitated by the relatively large amounts of sporopollenin that can be obtained.

I thank A. Amagai of Kyoto University for generously providing the D. mucoroides 7 mutant (MF-1) and $\mathrm{H}$. Hagiwara of National Science Museum for making Acytostelium irregularosporum available. I also gratefully acknowledge S. A. Salehi of Osaka University for reading and criticizing the manuscript. This work was in part supported by grants-in-aid (nos 58219003, 58540443) from the Ministry of Education of Japan and by a grant from Yamada Science Foundation.

\section{REFERENCES}

AmagaI, A. \& Filosa, M. F. (1984). The involvement of cyclic AMP and volatile substance(s) in the development of a macrocyst-forming strain of Dictyostelium mucoroides. Development, Growth and Differentiation (in the Press).

Brooks, J., Grant, P. R., Muir, M. D., van GiJzel, P. \& SHAW, G. (editors) (1971). Sporopollenin. London \& New York: Academic Press.

ErdtMan, G. (1960). The acetolysis method. A revised description. Svensk botanish tidskrift 54, 561-564.

FrancIS, D. W. (1979). True divergent differentiation in a cellular slime mold Polysphondylium pallidum. Differentiation 15, 187-192.

MacInnes, M. A. \& Francis, D. W. (1974). Meiosis in Dictyostelium mucoroides. Nature, London 251, 321323.

MAEDA, Y. (1984). The presence and location of sporopollenin in fruiting bodies of the cellular slime moulds. Journal of Cell Science 66, 297-308.

O'DAY, D. H. (1974). Intracellular and extracellular enzyme patterns during microcyst germination in the cellular slime mold Polysphondylium pallidum. Developmental Biology 36, 400-410.

Olive, L. S. (1975). The Mycetozoans. New York, San Francisco \& London: Academic Press.

Olive, L. S. \& Stoianovitch, C. (1960). Two nev members of the Acrasiales. Bulletin of the Torrey Botanical Club 87, 1-20.

RAPER, K. B. \& QUINLAN, M. S. (1958). Acytostelium leptosomum: a unique cellular slime mould with an acellular stalk. Journal of General Microbiology $\mathbf{1 8}$, $16-32$.

REYNolds, E. S. (1963). The use of lead citrate at high $\mathrm{pH}$ as an electron-opaque stain in electron microscopy. Journal of Cell Biology 17, 208-212.

Shaw, G. (1971). In Sporopollenin, pp. 305-348. Edited by J. Brooks, P. R. Grant, M. D. Muir, P. van Gijzel \& G. Shaw. London \& New York: Academic Press.

TOAMA, M. A. \& RAPER, K. B. (1967). Microcysts of the cellular slime mold Polysphondylium pallidum. I. Factors influencing microcyst formation. Journal of Bacteriology 94, 1143-1149. 